\title{
Identidades Docentes e Educação Básica: as vozes dos professores
}

\author{
Doris Maria Luzzardi Fiss* \\ Fernando Weiss Xavier**
}

\section{Resumo}

Este artigo tem como tema a produção das identidades docentes nos contextos da escola básica, objetivando compreender de que modo esse processo ocorre, buscando subsídios, sobretudo, em Maurice Tardif (2000, 2012), Maurice Tardif e Daniele Raymond (2000), Maria Manuela Alves Garcia, Álvaro Hypolito e Jarbas Vieira (2005). A pesquisa, realizada em 2013, tem um caráter qualiquantitativo. O tratamento dos dados ocorreu através da Análise de Conteúdo a partir da perspectiva de Laurence Bardin (1977). Os dados foram produzidos através de um roteiro de perguntas direcionadas a 50 professores da Educação Básica, os quais atuam em escolas da rede pública, privada ou ambas, localizadas em Porto Alegre e Região Metropolitana. As respostas dos professores indicam que a produção das identidades docentes, no âmbito da escola básica, ocorre tanto a partir das experiências pré-profissionais como das experiências profissionais. Apesar da influência das políticas públicas e das mudanças curriculares, o profissional da educação detém relativa autonomia em sua prática profissional. Como conclusão, observa-se que as identidades profissionais docentes são produzidas a partir de diversos fatores e saberes, tensões e contradições.

Palavras-chave: Identidade Docente. Escola Básica. Educação Contemporânea.

* Doutora em Educação pela Universidade Federal do Rio Grande do Sul (UFRGS). Professora do Departamento de Ensino e Currículo (DEC) e do Programa de Pós-Graduação em Educação (PPGEDU) da Universidade Federal do Rio Grande do Sul (UFRGS).

** Mestre em Planejamento Urbano e Regional pela Universidade Federal do Rio Grande do Sul (UFRGS). 


\section{Introdução}

Este artigo apresenta, como objetivo geral, compreender a produção das identidades docentes nos contextos da escola básica. Para isso, utilizamos, como referências principais, mas não exclusivas, estudos de Tardif (2000) e Tardif e Raymond (2000), a partir dos quais é feita a abordagem dos saberes profissionais dos professores e de sua relação com os conhecimentos universitários; outro estudo de Tardif (2012) em que é discutida a importância do saber experiencial na formação docente, fornecendo elementos para compreender o desprestígio que experimenta, atualmente, a docência; o estudo de Garcia, Hypolito e Vieira (2005) em que se apresenta uma abordagem diferente a respeito do tema da identidade profissional docente, definindo-a como uma construção social caracterizada por múltiplos fatores que interagem entre si; e, por último, o estudo de Lüdke e Boing (2004) no qual se aborda a (des)profissionalização da docência, partindo do ponto de vista de que o aspecto profissional compõe a identidade dos indivíduos e a precarização do trabalho do professor pode ter repercussão sobre a construção dessa identidade.

Estruturamos a discussão em algumas seções e subseções. A primeira seção, sob o título Saberes e identidades docentes, resgata modos de compreender tais identidades a partir de pesquisas desenvolvidas por estudiosos preocupados com o tema. A segunda, Metodologia, demonstra, a partir da interpretação das vozes de cinquenta professores, como eles percebem a si e ao seu fazer - o que é melhor apresentado na seção seguinte, Descobertas, que está dividida em três subseções, respectivamente: Prática do professor e identidade profissional; Saber docente, prática profissional e identidades; e Trabalho docente e políticas públicas.

Nas considerações finais, ou Conclusões, fechamos o texto, sinalizando que os achados desta pesquisa indicam ser a produção das identidades docentes, no âmbito da escola básica, influenciada por múltiplos fatores, tanto pré-profissionais como profissionais. Os professores e professoras, a despeito da influência das políticas públicas e das transformações da sociedade em função da globalização econômica, apresentam certa autonomia em sua prática profissional, cujos saberes e identidades advêm da experiência de vida e, com igual importância, da própria escola em que lecionam e de outros espaços formadores, fazendo-se de modo mestiço, heterogêneo.

O referido estudo decorre de investigação desenvolvida no ano de 2013. Do trabalho empírico derivaram dados nascidos de um exercício de escuta das vozes docentes a partir de roteiro de perguntas direcionadas a 50 professores da Educação Básica, os quais atuam em escolas da rede pública, privada ou ambas, localizadas em Porto Alegre (Rio Grande do Sul) e Região Metropolitana. O critério de 
escolha dos docentes foi, sobretudo, sua disposição para a conversa e a aproximação existente entre eles e os pesquisadores envolvidos. Após esclarecimentos no que tange ao foco da pesquisa, eles responderam às seguintes perguntas, dispostas em três eixos temáticos: 1) como a escola pode atrair a comunidade para o seu interior? E qual a tua participação nisto? 2) o que motiva o jovem a ir à escola? Quais as tuas estratégias para lidar com a desmotivação dos alunos? (E as da escola?) 3) na tua opinião, para que serve o conhecimento produzido na escola? (Eixo culturas juvenis); 4) tu já sofreste ou presenciaste algum tipo de violência? Como tu reagiste? Tu terias a mesma reação hoje? Por quê? 5) como a escola lida com os casos de violência? Como tu compreendes estas ações? 6) como é a relação da escola com a comunidade? Existe algum plano conjunto entre escola e comunidade para tratar questões de violência? Qual é a tua opinião sobre estas ações? (Eixo violência na/da/à escola); e 7) o que mudou em ti desde que tu iniciaste a trabalhar como professor? 8) o que fez tu te tornares um professor? Houve algum modelo (referência) profissional? Que influências tu acreditas que exerces sobre teus alunos? 9) tu percebes algum limite em tua atuação docente em função das políticas nacionais de educação? Que (quais) limite(s)? (Eixo identidades docentes). Para os fins deste artigo, serão considerados tão somente os depoimentos relacionados a este último eixo.

\section{Saberes e identidades docentes}

Tardif (2000; 2012) e Tardif e Raymond (2000), em suas pesquisas, abordam os saberes profissionais dos professores e sua relação com os conhecimentos universitários. Segundo Tardif (2000, p. 10), no que concerne aos saberes profissionais, manifesta-se a chamada "epistemologia da prática profissional" referente ao "estudo do conjunto dos saberes utilizados realmente pelos professores em seu espaço de trabalho cotidiano para desempenhar todas as suas tarefas". Ou seja, tratam-se de saberes que não necessariamente se fundamentam apenas no conhecimento acadêmico, compreendendo algo muito mais amplo: “[...] o saber docente se compõe, na verdade, de vários saberes [...]: os saberes disciplinares, curriculares, profissionais (incluindo os das ciências da educação e da pedagogia) e experienciais" (TARDIF, 2012, p. 33).

Todos estes saberes se referem diretamente à identidade profissional dos docentes e são de natureza tanto social quanto individual, sendo necessário considerar o sujeito desde as condições de produção de seu ofício e de sua existência: “[...] o saber dos professores é o saber deles e está relacionado com a pessoa e a identidade deles, com a sua experiência de vida e com a sua história 
profissional, com as suas relações com os alunos em sala de aula e com os outros atores escolares na escola, etc.” (TARDIF, 2012, p. 11, grifo do autor). Além disso, enfatizam-se duas constatações a partir desta abordagem epistemológica: a primeira diz respeito ao fato de "que os saberes profissionais dos professores são temporais, ou seja, são adquiridos através do tempo" (TARDIF, 2000, p. 13) e a segunda constatação propõe que "os saberes profissionais dos professores são variados e heterogêneos" (TARDIF, 2000, p. 14).

Em outro trabalho, Tardif e Raymond (2000) também tratam este tema, analisando a genealogia dos saberes docentes. Os autores abordam a trajetória pré-profissional e a trajetória profissional. Primeiramente, em relação à trajetória pré-profissional, grande parte do que os professores conhecem “sobre o ensino, sobre os papéis do professor e sobre como ensinar provém de sua própria história de vida, principalmente de sua socialização enquanto alunos" (TARDIF; RAYMOND, 2000, p. 216). Quanto à trajetória profissional, segundo Tardif e Raymond (2000, p. 217), “Os saberes dos professores são temporais, pois são utilizados e se desenvolvem no âmbito de uma carreira, isto é, ao longo de um processo temporal de vida profissional de longa duração [...]”. Verifica-se que o tempo apresenta importância central na análise sobre a identidade docente, haja vista que, pela própria natureza do trabalho pedagógico, a prática profissional se constitui em lócus privilegiado de desenvolvimento de "saberes oriundos do próprio processo de trabalho e nele baseados" (TARDIF; RAYMOND, 2000, p. 218).

Já Garcia, Hypolito e Vieira (2005, p. 54) apresentam uma abordagem complementar sobre o tema da identidade docente. Na visão dos autores, a identidade profissional dos docentes se define

[...] como uma construção social marcada por múltiplos fatores que interagem entre si, resultando numa série de representações que os docentes fazem de si mesmos e de suas funções, estabelecendo, consciente e inconscientemente, negociações das quais certamente fazem parte suas histórias de vida, suas condições concretas de trabalho, o imaginário recorrente acerca dessa profissão - certamente marcado pela gênese e desenvolvimento histórico da função docente - e os discursos que circulam no mundo social e cultural acerca dos docentes e da escola.

Conforme propõem, as diferentes formas de produção das identidades docentes se relacionam com os diversos tipos de profissionalismo: clássico, trabalho flexível, trabalho prático, trabalho extensivo, trabalho complexo.

O "profissionalismo clássico" encontra seu fundamento, principalmente, na existência de um conhecimento especializado, que se baseia na valorização da ciência e da técnica, e em aspectos éticoprofissionais regulados por órgãos: "na perspectiva do profisssionalismo clássico, a relação com a comunidade será sempre uma relação formal e de submissão ao conhecimento técnico dos 
profissionais" (GARCIA; HYPOLITO; VIEIRA, 2005, p. 50). Ou seja, defende-se a neutralidade da ciência, fundamentalmente. ${ }^{1}$

O "profissionalismo como trabalho flexível” tem sua noção focada "na redefinição dos aspectos técnicos do trabalho docente de acordo com uma estratégia de desenvolvimento de culturas de colaboração e de comunidades profissionais solidárias" (GARCIA; HYPOLITO; VIEIRA, 2005, p. 50). Dessa forma, implica em uma relativização do conhecimento científico: "A noção de profissionalismo e profissionalização concebidos a partir das comunidades docentes locais substitui os princípios das "certezas científicas" por princípios das "certezas situadas" como base para o profissionalismo docente [...]” (GARCIA; HYPOLITO; VIEIRA, 2005, p. 50).

O "profissionalismo como trabalho prático" entende que a docência se constitui como uma atividade cujos saberes são coincidentes com os saberes práticos, experienciais, que são formados por valores e propósitos de professores ${ }^{2}$, os quais constroem suas próprias práticas de educação, conforme afirmam Garcia, Hypolito e Vieira (2005). Os autores argumentam que uma extensão considerável desse discurso refere-se à noção de "prática reflexiva", a qual produz a concepção de docente como "prático-reflexivo" (GARCIA; HYPOLITO; VIEIRA, 2005, p. 51). Este tipo de profissionalismo propõe uma constante reflexão e crítica a respeito das ações docentes, o que contribui para questionar o conhecimento como saber científico e, por consequência, gera maior consciência crítica sobre a realidade.

No "profissionalismo como trabalho extensivo", segundo Garcia, Hypolito e Vieira (2005), as habilidades dos professores se originam da mediação entre teoria e experiência, e a visão dos docentes ultrapassa a sala de aula, alcançando o contexto social mais amplo da educação. Assim, percebe-se a sala de aula em sua relação com outros acontecimentos da escola, e as metodologias de trabalho constituem o resultado da interação com a comunidade docente, inclusive valorizando-se outras atividades como, por exemplo, literatura da área ou atividades de formação em serviço. Consoante uma tal compreensão, "o ensino é visto como atividade racional mais do que intuitiva" (GARCIA; HYPOLITO; VIEIRA, 2005, p. 51).

Quanto ao "profissionalismo como trabalho complexo", este surge a partir das transformações causadas pela globalização e pelas mudanças econômicas globais e locais, as quais têm afetado o trabalho docente. Os autores assinalam que certos pesquisadores pensam que o trabalho docente deve ser percebido como trabalho de grande complexidade e, por conseguinte, julgado pelo caráter complexo das tarefas, que, de uns tempos para cá, incluem "planejamento coletivo, poder de decisões, 
uso de computadores, avaliação com portfólio, avaliação colaborativa" (GARCIA; HYPOLITO; VIEIRA, 2005, p. 53) e assim por diante. Nesse caso, conquanto a inflação de tarefas possa resultar em aumento do profissionalismo, corre-se o risco de ela atingir o docente em sua saúde e gerar situações tanto de exploração abusiva do trabalho quanto de mal-estar físico e psicológico.

Para além do profissionalismo e seus desdobramentos na realidade da educação básica, também se torna importante abordar a desprofissionalização da docência. Lüdke e Boing (2004) analisam se, e de que maneira, a precarização do trabalho docente pode repercutir sobre a construção da identidade dos professores. Os autores abordam este tema a partir das pesquisas de dois autores franceses: Isambert-Jamati ${ }^{3}$, que investigou, durante 40 anos, a formação e o trabalho dos professores; e Claude Dubar $^{4}$, com pesquisas no campo da socialização profissional.

Viviane Isambert-Jamati trata da "desprofissionalização" do magistério, destacando que, possivelmente, tenha ocorrido um retrocesso no processo de profissionalização dos docentes na França. Tratando particularmente dos professores do ensino fundamental, a referida autora propõe diversas características que se orientam para o sentido da profissionalização, e outras que se orientam para o sentido inverso:

No sentido positivo alinham-se o sentimento de responsabilidade sobre um serviço, uma missão, mesmo se o tom sagrado da vocação tenha desaparecido; a busca de uma formação em "psicopedagogia" e de uma experiência, como representando uma competência própria de especialistas da infância; a diminuição do recrutamento dos sem-formação; o aumento rápido do número de anos de estudo; e a tendência a se especializar, a dividir o trabalho entre francês, ciências etc. No sentido inverso estão: a formação feita por um grupo de outro meio, o que diminui a autonomia do grupo profissional; a remuneração considerada muito abaixo de sua qualificação; a diversidade das formações e de experiências de cada um, inclusive profissional; a multiplicidade de vias de formação, sacrificando o aspecto globalmente socializador; e a dessindicalização. (LÜDKE; BOING, 2004, p. 1162-1163).

Em relação aos professores do ensino secundário, no sentido da profissionalização, atualmente existem: a formação longa como regra; a boa regulamentação da profíssão com uma seleção rígida, através de concurso de entrada sob responsabilidade de "colegas" do ensino superior; a grande autonomia para escolher os métodos e programas; a tendência de ida para as classes mais elevadas; "a existência de associações de especialistas, que confirma a concentração nas áreas de conhecimento; a palavra de ordem sindical de um ensino 'de alto nível'; e uma tomada de distância com relação aos professores primários" (LÜDKE; BOING, 2004, p. 1163).

Por último, os autores também discorrem a respeito da precarização profissional sob o argumento de que a atuação dos professores está dentro de um sistema subordinado à regularização 
pelo Estado, o qual estabelece limites à sua autonomia como grupo ocupacional (LÜDKE; BOING, 2004). Fiss (2003, p. 164), retomando pesquisa desenvolvida entre 1996 e 2003 junto a um grupo de 36 professores que atuam em escola da rede pública estadual localizada na região central de Porto Alegre (Rio Grande do Sul), comenta essa situação, acrescentando que:

O sistema escolar, primeiro, admite a competência dos professores, tanto que lhes possibilita o estabelecimento de um vínculo de trabalho e coloca-os na posição de trabalhadores da educação aptos a exercer as funções atinentes a tal papel. Pouco depois, ataca esses profissionais de formas variadas que questionam a referida competência. Seria dizer que [...] deixa de tratá-los como profissionais [...]. ${ }^{5}$

O fato de os professores trabalharem em um mesmo estabelecimento também traz como consequência "inúmeras influências sobre a atuação dos profissionais da educação, integrados em uma rede de interação com colegas, alunos, funcionários, pais, enfim, um microcosmo que é preciso conhecer de perto para se entender melhor essa ocupação" (LÜDKE; BOING, 2004, p. 1163). Soma-se a tal constatação uma outra: a da possibilidade, ainda presente, de estabelecimento de uma relação que, transcendendo o mal-estar, constitua-se a partir da pertença à profissão pelo enfrentamento dos desafios que lhe são próprios.

Outro autor francês que trata sobre o processo de desprofissionalização da docência, segundo Lüdke e Boing (2004), é Claude Dubar (1991, 1997), que, a partir de discussão teórica e de investigação em diversos grupos de trabalhadores do setor empresarial, "propõe uma visão sobre o processo de construção identitária, envolvendo, ao mesmo tempo e ao longo do tempo, várias facetas em interação constante" (DUBAR apud LÜDKE e BOING, 2004, p. 1166). Destaca-se a importância atribuída pelo autor ao aspecto profissional como um dos principais elementos da identidade dos indivíduos. A questão das identidades profissionais é focada por este autor, assim, atravessada por uma noção de trabalho, que é visto como em plena transformação. Conforme Lüdke e Boing (2004, 1167), de uma obrigação estabelecida formalmente e à qual se deve obediência, o trabalho se torna "um universo de obrigações implícitas, de investimento pessoal, cercado de incertezas e dependente da criatividade individual e coletiva". Trata-se do que se convencionou chamar de "modelo da competência" (idem, 2004, p. 1167), o qual se expressa a partir de qualidades que se espera de todos os assalariados, como, por exemplo, iniciativa, responsabilidade e trabalho em equipe.

Lüdke e Boing (2004) argumentam que, segundo Dubar, a noção de trabalho se transforma em uma relação de serviço, em todos os setores, nas grandes, médias e pequenas empresas e até mesmo nas funções públicas. Dubar afirma que, nos últimos 30 anos, todas essas transformações desmantelaram 
setores inteiros da economia na França. A partir disso, desmantela-se, para o trabalhador, um modo de praticar seu ofício e constituir e estruturar sua vida a partir dele, de seus valores e formas de ser e fazer, construídos de modo coletivo e passados, diversas vezes, de gerações para gerações. As mudanças no mercado de trabalho determinaram uma crise das identidades profissionais:

Entram em crise as identidades "categoriais" de ofício, ligadas a uma organização mais aproximada do tipo comunitário. Entram em cena as identidades construídas a partir de conflitos sociais, mais de origem "profissional", de coletivos de assalariados, não se caracterizando como "lutas de classe". [...] É um elemento crucial do que o autor chama de "crise das identidades profissionais". (LÜDKE e BOING, 2004, p. 11671168).

Em estudo mais recente, Tardif (2012) volta a tratar da relação entre a identidade profissional docente e os saberes que a envolvem. Segundo o autor, de maneira geral, pode-se afirmar que os professores ocupam uma posição estratégica, mas socialmente desvalorizada, entre os diversos grupos que atuam, de uma forma ou de outra, no campo dos saberes. Pode-se dizer que esta desvalorização não é perceptível por quem é leigo nas questões sobre educação, ao contrário do que ocorre com a questão salarial.

Na verdade, os saberes da formação profissional (das ciências da educação e da pedagogia), os saberes disciplinares (e específicos de cada área do conhecimento) e os saberes curriculares (ou programas escolares) dos docentes parecem sempre ser produzidos por outro grupo profissional, incorporando-se de maneira efetiva na prática docente, sem serem, entretanto, produzidos ou legitimados por ela. Portanto, não se verifica uma apropriação dos saberes por parte do grupo profissional que mais teria autoridade para deles tratar. Segundo Tardif (2012, p. 40), "a relação que os professores mantêm com os saberes é a de 'transmissores', de 'portadores' ou de 'objetos' de saber, mas não de produtores de um saber ou de saberes que poderiam impor como instância de legitimação social de sua função e como espaço de verdade de sua prática”. O autor argumenta que, na impossibilidade de o professor controlar os saberes disciplinares, curriculares e da formação profissional, ele produz ou tenta produzir saberes por meio dos quais busca compreender sua prática.

Tais saberes tornam possível ao professor, em contrapartida, distanciar-se daqueles adquiridos fora dessa prática. Dessa forma, adquirem grande importância os chamados saberes experienciais ou, segundo Tardif (2012, p. 48), o "conjunto de saberes atualizados, adquiridos e necessários no âmbito da prática da profissão docente e que não provêm das instituições de formação nem dos currículos". O autor expõe que estes não são sistematizados em doutrinas ou teorias, constituindo-se como saberes práticos, que também configuram "um conjunto de representações a partir das quais os professores 
interpretam, compreendem e orientam sua profissão e sua prática cotidiana em todas as suas dimensões" (TARDIF, 2012, p. 48-49).

\section{Metodologia}

A pesquisa aqui referida tem um caráter quali-quantitativo. Quanto à sua dimensão qualitativa, ela enfoca "o universo dos significados, dos motivos, das aspirações, das crenças, dos valores e das atitudes" (MINAYO, 2007, p. 21) assumidos pelos professores entrevistados. Como esclarece Minayo (2007), uma pesquisa com tal característica se constitui a partir de algumas etapas: fase exploratória (estabelecimento do objeto de estudo, das questões de pesquisa, dos objetivos e fundamentos teóricometodológicos); trabalho de campo (campo empírico e produção dos dados); análise dos dados produzidos.

A partir das questões formuladas aos professores do ensino básico e das leituras sobre identidades docentes, estabelecemos seis categorias a partir das quais foram realizadas análises de 168 depoimentos de um conjunto de 450 obtidos por meio de entrevista. ${ }^{6}$ A este respeito, cabe destacar que algumas respostas assumiram a forma de narrativas um pouco mais longas, nas quais os professores amalgamavam dados de seu mundo social e cultural, o que possibilitou ter acesso privilegiado a modos de escrita de si, a partir dos quais estes profissionais "inventam” a docência.

A metodologia para a definição das categorias foi estabelecida a partir da Análise de Conteúdo (AC) proposta por Laurence Bardin (1977). A autora afirma que a AC se refere a um conjunto de técnicas de análise das comunicações, porém "não se trata de um instrumento, mas de um leque de apetrechos; ou, com maior rigor, será um único instrumento, mas marcado por uma grande disparidade de formas e adaptável a um campo de aplicação muito vasto: as comunicações" (BARDIN, 1977, p. 31). Atualmente, de forma geral, o termo análise de conteúdo apresenta a seguinte definição e objetivo:

Um conjunto de técnicas de análise das comunicações visando obter, por procedimentos, sistemáticos e objetivos de descrição do conteúdo das mensagens, indicadores (quantitativos ou não) que permitam a inferência de conhecimentos relativos às condições de produção/recepção (variáveis inferidas) destas mensagens. (BARDIN, 2005, p. 42).

Ainda segundo a autora, o gênero de resultados que se obtém pelas técnicas de AC não pode ser considerado prova irrefutável. Entretanto, "constitui, apesar de tudo, uma ilustração que permite corroborar, pelo menos parcialmente, os pressupostos em causa” (BARDIN, 1977, p. 81). 
As questões enfocadas neste artigo integram um roteiro organizado em 3 eixos temáticos (juventudes e escola, violência e escola, identidades docentes). Para os fins pretendidos aqui, foram consideradas tão somente as análises referentes a depoimentos provocados por questionamentos pertencentes ao terceiro eixo, ou seja, identidades docentes: o que mudou em ti desde que tu iniciaste a trabalhar como professor? O que fez tu te tornares um professor? Houve algum modelo (referência) profissional? Que influências tu acreditas exercer sobre teus alunos? Tu percebes algum limite em tua atuação docente em função das políticas nacionais de educação? Que (quais) limite(s)?

Como dito antes, foi analisado um total de 168 depoimentos produzidos por 50 professores. Dos 50 professores entrevistados, nem todos informaram gênero, tipo de escola em que trabalham e sua localização. Considerando tal situação, conseguimos depreender que: dos 36 docentes que informaram seu gênero, a maioria são mulheres (21 contra 14 homens); dos 40 que informaram o tipo de escola, 30 lecionam na rede pública, 6 atuam em ambas as redes; e 4, apenas na rede privada; e, dos 25 que informaram localização da escola, 20 trabalham em escolas situadas em Porto Alegre (Rio Grande do Sul), enquanto 5 estão lotados em instituição localizada na Região Metropolitana.

Os depoimentos foram compreendidos a partir das categorias apresentadas a seguir. Ressaltamos que elas não excluem uma à outra, de modo que encontramos, em alguns depoimentos, elementos pertencentes a mais de uma categoria identificada, remetendo a um contexto de produção de identidades docentes mestiças:

Quadro 1 - Questões e categorias de análise

\begin{tabular}{|l|l|}
\hline \multicolumn{1}{|c|}{ Questões } & \multicolumn{1}{c|}{ Categorias } \\
\hline O que mudou em ti desde que tu iniciaste a trabalhar como professor? & $\begin{array}{l}\text { Docência como saber acadêmico } \\
\text { Docência como saber prático }\end{array}$ \\
\hline $\begin{array}{l}\text { O que fez tu te tornares um professor? Houve algum modelo (referência) } \\
\text { profissional? Que influências tu acreditas exercer sobre teus alunos? }\end{array}$ & $\begin{array}{l}\text { Saberes da trajetória pré-profissional } \\
\text { Saberes da carreira }\end{array}$ \\
\hline $\begin{array}{l}\text { Tu percebes algum limite em tua atuação docente em função das políticas } \\
\text { nacionais de educação? Que (Quais) limite(s)? }\end{array}$ & $\begin{array}{l}\text { Ausência de Influências } \\
\text { Crítica às Políticas }\end{array}$ \\
\hline
\end{tabular}

Fonte: Elaborados pelos autores (2017). 


\section{Descobertas}

\subsection{Prática do professor e identidade profissional}

A partir da questão o que mudou em ti desde que tu iniciaste a trabalhar como professor?, identificamos duas categorias relacionadas à prática de ensino do professor e sua identidade profissional: docência como saber acadêmico e docência como saber prático.

A docência como saber acadêmico foi surpreendida em depoimentos em que o professor destaca que sua atividade profissional está fundamentada na docência considerada a partir das experiências de formação inicial e/ou continuada - o que pode ser evidenciado nos enunciados a seguir ${ }^{7}$ :

No início a gente é insegura, mas, à medida que nos aperfeiçoamos e nos aprimoramos, ficamos mais seguras. (Anita).

Para o meu fazer docente e aplicar meus propósitos em sala de aula, me apoio nos ensinamentos e na trajetória de Paulo Freire, em que faz a discussão sobre o sentido de ensino e de identidade docente. (Isabel).

Com o passar do tempo, tenho tentado aprimorar minha metodologia didática, pois tenho notado o crescente desinteresse dos alunos em sala de aula. (Lucas).

Anita afirma, inicialmente, que o aperfeiçoamento e o aprimoramento a tornaram mais segura para ministrar aulas. Isabel se apoia nos ensinamentos e na trajetória de Paulo Freire para conduzir as aulas. Lucas fala em tentativa de aprimorar a metodologia. Enfim, os depoimentos remetem a um diálogo com o saber científico da área educacional, a significados que lembram formação continuada, necessidade de estudo constante e busca de apoio nele como saberes mais próximos da didática, ou seja, coisas-a-saber muito presentes nas discussões acadêmicas em períodos de formação docente inicial e continuada.

Tais depoimentos indiciam significados que lembram a atividade profissional destes professores a partir de sua relação com o saber acadêmico, no entanto sem deixar de se apoiar no saber experiencial. Na continuação dos depoimentos, Anita complementa: “Antes eu dava a matéria programada. Hoje dou a mesma matéria, mas construo o conteúdo com base no saber dos alunos, contextualizo muito mais, mas isto porque adquiri mais experiências e conhecimentos." O que encontra eco em Tardif e Raymond (2000), que definem os saberes profissionais dos professores de duas maneiras: temporais, ou seja, adquiridos por meio do tempo, e variados e heterogêneos. Além disso, Tardif (2012) pontua que, considerando que o saber docente é atravessado por saberes de variadas 
fontes - disciplinares, curriculares, profissionais e experienciais -, a relação dos docentes com estes saberes não pode se restringir a uma prática transmissora, a um "dar a aula programada".

Hoje, se exige do educador que amplie sua interlocução e acolha outros dizeres e outras vozes no universo plural de "invenção" da docência e de escrita de si, de modo a investir num processo de produção de saberes através do qual melhor compreenda sua prática e a legitime desde um lugar de reconhecimento social de seu valor. Tais elementos estão presentes no enunciado de Anita: ao mesmo tempo em que destina aos saberes profissionais (ou conhecimentos universitários, acadêmicos) um lugar privilegiado, deixa escapar certa consideração pelas experiências adquiridas, portanto não descarta nem a uns nem a outros. Nessa esteira, em outros depoimentos, os professores revelam perceber sua atividade profissional como um saber-fazer fundado na prática, na experiência:

Desde que eu comecei a dar aula eu peço aos alunos uma avaliação do meu desempenho e do deles, me dei conta que eu era muito preocupada em passar conteúdo e eles me disseram que eu falava pouco de mim, passei a compartilhar algumas coisas da minha vida e eles da deles [...]. (Júlia).

No início há uma certa insegurança, tanto em termos de conteúdo quanto em lidar com os alunos e o domínio de sala de aula. Mas os anos vão passando e a gente vai realmente se tornando professor. Penso que, a cada ano, tenho um maior crescimento. A cada ano fui uma professora melhor que no ano anterior. (Mariana).

[...] a experiência vai te moldando! E nada melhor do que a prática. Mas sem dúvida o dia a dia em sala de aula me deixou mais tolerante com todas as pessoas e didaticamente me ensinou a ouvir mais os alunos. (Pedro)

Júlia fala que mudou seu estilo de ensinar ao adquirir experiência profissional, aprendeu a tornar-se mais amiga dos alunos. Mariana afirma que, no início, era insegura, mas, ao longo do tempo, foi adquirindo experiência e realmente tornou-se "uma professora". Pedro argumenta sobre a importância da experiência, da prática em sala de aula, que o deixou mais tolerante com as pessoas e o ensinou a ouvir mais os alunos. Pelo que se depreende dos depoimentos analisados, a compreensão da atividade profissional manifestada pelos professores também encontra ressonância em Tardif e Raymond (2000), contudo, neste caso em específico, os enunciados indiciam maior aproximação dos saberes experienciais do que dos conhecimentos universitários. Demandas surgidas na prática das relações cotidianas com os educandos produzem transformações nos modos como o professor se constitui e afetam sua identidade tanto quanto a experiência conquistada com o passar do tempo, porque

[...] as situações de trabalho exigem dos trabalhadores conhecimentos, competências, aptidões e atitudes específicas que só podem ser adquiridas e dominadas em contato com essas mesmas situações [...]. Essas situações exigem [...] saberes mobilizados e empregados na prática cotidiana, saberes esses que dela se originam, de uma maneira ou de outra, e que servem para resolver os problemas dos professores em exercício e 
para dar sentido às situações de trabalho que lhes são próprias. (TARDIF e RAYMOND, 2000, p. 218).

Sacristán (2003) reitera tal argumento quando propõe pensar o ensino como atividade profissional desde quatro perspectivas: o ensino como repertório de esquemas práticos; as articulações constituídas entre esquemas práticos (rotinas) e esquemas estratégicos (“ordem em que se apoia o desenvolvimento da acção") nas atividades de ensino; o ensino como ciência aplicada; e o ensino como empenhamento moral com destaque para a dimensão ética da atividade docente. A referência a esquemas práticos, entretanto, não significa a dominância dos saberes experienciais sobre saberes de outra ordem, ou o contrário, mas a necessária superação do entendimento de prática enquanto organização técnica de dispositivos de ensino, com o reconhecimento da prática educativa enquanto práxis, ou seja, trabalho que demanda reflexão sobre o próprio fazer, afetado pelas muitas condições de produção da existência pelos professores.

\subsection{Saber docente, prática profissional e identidades}

A partir das questões o que fez tu te tornares um professor? Houve algum modelo (referência) profissional? Que influências tu acreditas exercer sobre teus alunos?, enfocamos a influência dos diferentes tipos de saberes sobre a prática profissional do professor e sua identidade. A análise permitiu a identificação de duas categorias a partir das quais se pode discorrer sobre a prática de ensino do professor e sua identidade profissional, quais sejam: os Saberes da Trajetória Pré-Profissional e os Saberes da Carreira.

Em seus depoimentos, os professores ressaltam que seu saber tem influência da sua trajetória de vida pré-profissional:

Não tenho referência nenhuma na família, inclusive meu pai queria que eu fosse engenheira, mas eu sabia o que queria, vim para Porto Alegre morar na casa da minha avó porque queria fazer magistério e sabia até em qual escola. Quando eu tinha 10 anos, alfabetizei a empregada da minha casa. Acredito que influencio meus alunos pelo afeto, por ter uma relação próxima, por tocar neles. [...] é preciso fazer parte, conhecer sua história e a da sua família, trazer as coisas da vida. (Marta).

Sempre tive vontade de ser professora, era vocação mesmo. Tive excelentes professores, mas não acho que foram referências, pois sempre tive o desejo de estar em sala de aula desde pequenininha. Quanto à influência que exerço nos alunos, espero despertar boas coisas, acredito sinceramente que consigo influenciar positivamente, ao longo destes anos já tive excelentes retornos de alunos que passaram por mim. (Pedro). 
Marta afirma que já sabia da sua vocação para o ensino desde muito jovem, tendo, inclusive, alfabetizado a empregada da casa aos dez anos de idade. Ela destaca que influencia seus alunos através de uma relação de afeto. Pedro também diz que sempre teve vocação para a docência. Tais depoimentos apontam para a abordagem de Tardif e Raymond (2000) a respeito da genealogia dos saberes docentes, especialmente no que tange à observação de que muitos professores desenvolvem importante relação afetiva com os estudantes. Além disso, os autores observam que os professores conferem grande importância à sua personalidade; alguns chegam a dizer que foram feitos para ensinar, sentimento esse que "tende a naturalizar o saber-ensinar e a apresentá-lo como sendo inato" (TARDIF, 2000, p. 222). Entretanto essa personalização pode também ocultar o fato de que o saber-ensinar dos professores é adquirido ao longo do tempo, vinculado à história de vida e ao processo de socialização destes profissionais, e, também, o fato de que este processo resulta em práticas que, muitas vezes, reproduzem os papéis e rotinas institucionalizados da escola, conforme argumentam Tardif e Raymond (2000).

Em alguns depoimentos, os professores sublinham que o saber docente tem influência da trajetória de vida escolar:

Eu sempre achei legal muitos dos meus professores e acho que eles me incentivaram de alguma forma a ser professor. Eu só fui pensar em ser professor quando entrei para a faculdade de história e daí acabei fazendo licenciatura, mas nada muito planejado. Acabei dando aula para começar a trabalhar para pagar meus estudos e gostei da coisa. Quando vi já era professor e nem me dei conta. (Tiago).

Tiago assinala que admirava muitos de seus professores, especulando que pode ter sido influenciado por eles. Tardif e Raymond (2000) e Tardif (2012) lembram que os saberes dos professores são adquiridos através do tempo; nesse caso, destacam-se os saberes provenientes da formação escolar anterior, os saberes que provêm da formação profissional para o magistério e os saberes provenientes de sua própria experiência na profissão, na sala de aula e na escola. A referência de Tiago aos seus professores do passado, sob certo aspecto, confirma as considerações feitas pelos autores.

\subsection{Trabalho docente e políticas públicas}

A partir da pergunta tu percebes algum limite em tua atuação docente em função das políticas nacionais de educação? Que (quais) limite(s)?, avaliamos o quanto as políticas nacionais afetam o 
trabalho desses educadores. Ao analisar os depoimentos, definimos duas categorias: ausência de Influências e crítica às políticas.

No que concerne à ausência de influências, alguns professores responderam que não sentem nenhuma influência visível ou perceptível na sua atuação devido às políticas nacionais, em relação às suas aulas ou ao seu espaço escolar - o que se observa, por exemplo, no enunciado de Mário: "Não, o professor ainda pode fazer as coisas da sua maneira. Não são normas, diretrizes, parâmetros que mudam a mente de um professor. Somente a formação constante e de boa qualidade que pode mudar algo dentro da mente do professor" e em outros 15 depoimentos. Mário diz que suas ideias não são construídas a partir das normas ou diretrizes estabelecidas. Ele acredita que o professor usará de sua experiência e da educação como fatores mais fortes no momento de sua atuação.

Os depoimentos considerados aqui remetem ao tema da influência das políticas públicas sobre a atividade docente, o que encontra respaldo na abordagem de Garcia, Hypolito e Vieira (2005). Os autores expõem que a gestão da identidade profissional dos docentes constitui uma tarefa central no governo e na administração do sistema educacional e escolar de uma nação, sendo que "definir pelo discurso que categoria é essa, como deve agir, quais suas dificuldades e problemas é produzir uma parcela das condições necessárias à fabricação e à regulação da conduta desse tipo de sujeito" (GARCIA; HYPOLITO; VIEIRA, 2005, p. 47). Entretanto, conforme indicam os depoimentos dos profissionais entrevistados, as políticas públicas não determinam totalmente a atuação dos professores e das professoras, o que vem ao encontro da abordagem dos referidos autores:

[...] as identidades docentes não se reduzem ao que os discursos oficiais dizem que elas são. Eles são mais que meros formadores de cidadãos, como querem as políticas curriculares oficiais. Negociam suas identidades em meio a um conjunto de variáveis como a história familiar e pessoal, as condições de trabalho e ocupacionais, os discursos que de algum modo falam do que são e de suas funções. (GARCIA et al, 2005, p. 48).

Portanto, existe certa autonomia para os professores inventarem seu próprio modo de ministrar as aulas, através da negociação das suas respectivas identidades profissionais com os parâmetros estabelecidos pelas políticas educacionais. Ainda neste estudo, os autores entendem a identidade profissional como:

[...] as posições de sujeito que são atribuídas, por diferentes discursos e agentes sociais, aos professores e às professoras no exercício de suas funções em contextos laborais concretos. Refere-se ainda ao conjunto das representações colocadas em circulação pelos discursos relativos aos modos de ser e agir dos professores e professoras no exercício de suas funções em instituições educacionais, mais ou menos complexas e burocráticas. (GARCIA; HYPOLITO; VIEIRA, 2005, p. 48). 
Dessa forma, a noção de identidade profissional também pode ser apreendida através da análise do processo de construção interna do currículo, o qual, a partir de Sacristán (2008, p. 101), é definido "como um objeto que cria em torno de si campos de ação diversos, nos quais múltiplos agentes e forças se expressam em sua configuração, incidindo sobre aspectos distintos". A análise do processo de construção curricular envolve sua compreensão em níveis ou dimensões. Sacristán (2008), através do esquema a seguir exposto (Figura 1), propõe um modelo para interpretar o currículo como algo concebido no cruzamento de influências e campos de atividade diversificados e inter-relacionados:

Figura 1 - A objetivação do currículo no processo de seu desenvolvimento.

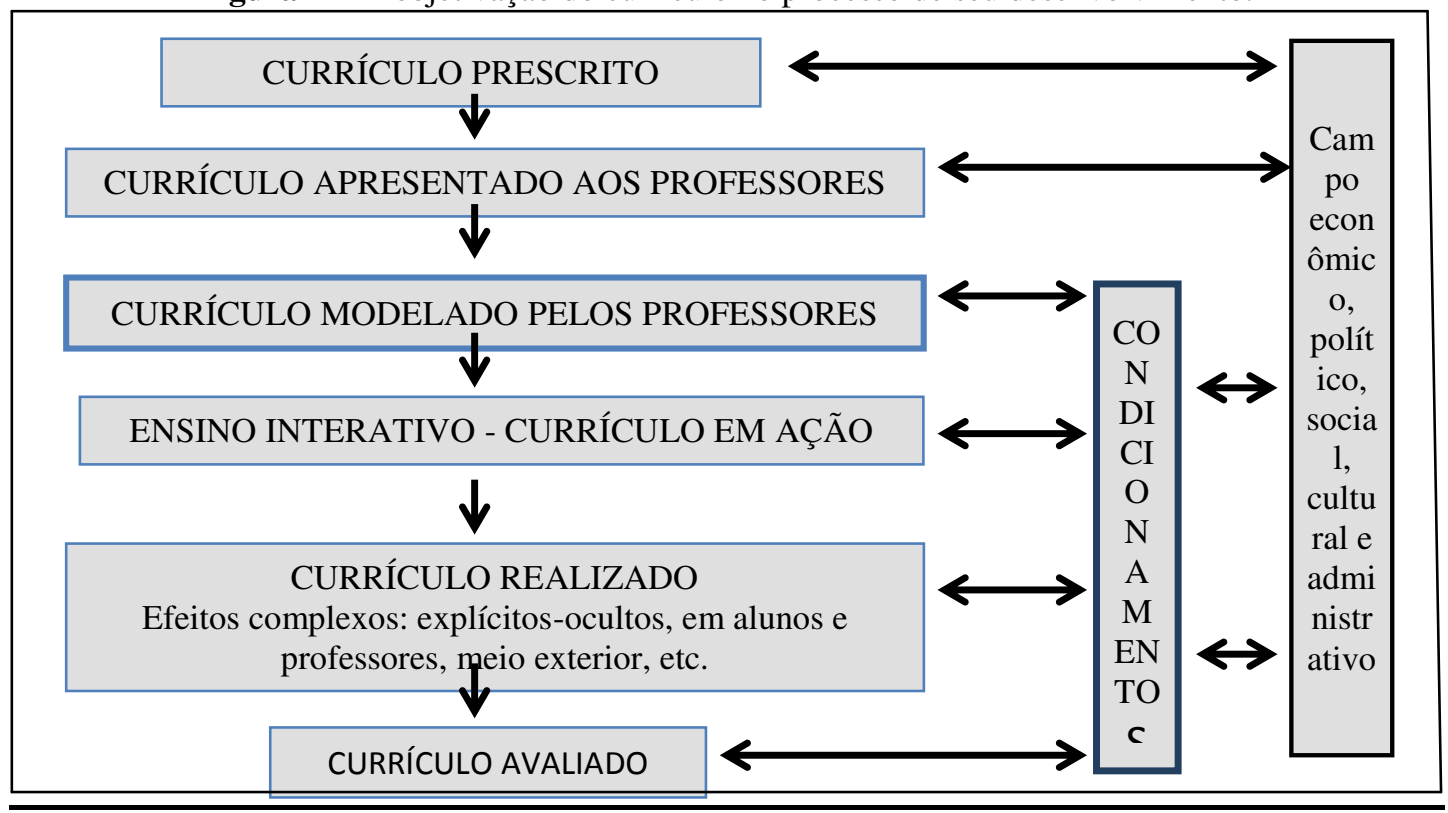

Fonte: Sacristán (2008, p. 105).

Segundo Sacristán (2008), apesar de parecer um modelo de dependências lineares e hierarquizadas, este esquema serve para demonstrar esferas de autonomia que representam, na realidade, forças concorrentes. Ou seja, "com diferente grau e força de influência entre elementos, trata-se de um modelo cujas fases têm inter-relações recíprocas e circulares entre si” (SACRISTÁN, 2008, p. 104). Entre os diversos níveis de objetivação do currículo, descritos pelo referido autor, neste artigo é importante discorrer sobre o currículo prescrito e o currículo moldado pelos professores.

O currículo prescrito diz respeito a algum tipo de prescrição ou orientação do sistema educativo quanto ao que deva ser seu conteúdo. Define-se, segundo Sacristán (2008), como aspectos que atuam como referência na ordenação do sistema curricular, sendo utilizado com o objetivo de referenciar o controle de materiais, controle de sistema etc. O currículo moldado pelos professores remete a um nível de objetivação do currículo em que o professor se constitui como um agente ativo bastante decisivo na 
concretização dos conteúdos e significados dos currículos, configurando, a partir de sua cultura profissional, qualquer proposta que lhe é realizada, "seja através da prescrição administrativa, seja do currículo elaborado pelos materiais, guias, livros-texto etc.” (SACRISTÁN, 2008, p. 105). O professor se constitui como um tradutor que interfere na configuração dos significados das propostas curriculares, sobretudo através do plano de ensino que elabora.

No entanto, conquanto perceba-se a afirmação da ausência (ou relatividade) de influência das políticas sobre o fazer docente em alguns depoimentos, em outros, os professores fazem a crítica às mesmas políticas:

As políticas nacionais vêm muito descaracterizadas. Falta uma identidade filosófica de papel da escola e do ensino para o Brasil, falta também uma política de estado para isso, essa é a que vamos seguir nos próximos 20 anos, vamos reavaliar isso e fazer uma proposta de política de estado, que é do que carecemos, não de governo [...]. É lamentável a cada governo trocar as políticas de educação. Devemos ter uma cultura educacional, [...] levantar uma causa nacional de organização da educação, estudar o que queremos do nosso ensino, para onde queremos chegar? Estabelecer metas, causas, consequências... Não consigo identificar essas políticas públicas. Ficamos nesta falta de... fazer um debate social, mas escutar o professor que está aqui embaixo [...]. (Antônio).

A falta de trabalho de base para a reestruturação da educação pública fez com que diversas iniciativas da escola fossem mal planejadas e trouxessem diversos problemas práticos. Eu não tenho uma longa trajetória como docente na rede estadual, mas escuto colegas que lecionam há mais de 15 anos se queixarem que nunca tiveram tanta sobrecarga de trabalho. E o pior, eles não garantem que essa sobrecarga é revertida em qualidade no ensino de seus alunos(as). Algumas das questões trazidas por esta reforma são de fato interessantes e fazem parte de concepção de ensino vindas das diretrizes nacionais. Na verdade, considero necessário construir um debate permanente sobre as políticas nacionais para que possamos construir conjuntamente uma educação pública de qualidade. (Carlos).

Antônio fala em falta de planejamento, que não se faz planos de longo prazo para a educação e que mudam constantemente os projetos de educação a cada tempo. Ele expõe esta questão como uma das maiores limitações de planos nacionais, pois interfere na educação como um todo. A análise do conteúdo desta fala permite concluir que a insatisfação com as políticas educacionais está fundamentalmente vinculada à cultura administrativa de não continuidade dos projetos governamentais após trocas de gestão. Por último, a resposta de Carlos deixa evidente que falta maior diálogo e debate do governo com os professores e a sociedade de um modo geral sobre os rumos da política educacional. Esta fala revela uma falta de identidade entre as expectativas da escola, consideradas desde a percepção dos professores e de outros integrantes da comunidade, e os rumos mais amplos da educação no Brasil, considerados desde as exigências e regulações estabelecidas pelos atos legais. 


\section{Conclusões}

Os saberes mobilizados pelos docentes em suas aulas são de diferentes tipos, destacando-se aqueles adquiridos com a experiência pré-profissional e os saberes cuja fonte é a experiência profissional da carreira docente. Dito de outra forma, no momento em que encontramos, nos depoimentos dos professores participantes da pesquisa, referências à docência como saber acadêmico e também como saber prático, é possível especular que eles (os respondentes) constituam a si, à sua identidade e ao seu fazer desde uma atitude intervalar de sujeito que se movimenta por mais de uma concepção. Importante salientar que, por serem fluidos esses deslocamentos, as concepções não estabelecem antagonismos entre si, mas instigam a ressignificar a docência desde uma perspectiva que, ao reconhecer o valor dos saberes universitários e dos saberes práticos, afirma a importância da capacidade reflexiva e das dificuldades quando consideradas como desafios à tomada de decisões, à correção de itinerários e à produção da docência como escrita de si.

Além disso, constatou-se, a partir deste estudo, que existe a percepção de um processo de precarização do ensino público, o que tem influenciado a produção de uma identidade profissional docente que se fundamenta no reconhecimento de que a educação deve ser mais valorizada pelas políticas públicas. Entretanto, apesar desta realidade de precarização do ensino e das críticas formuladas, os professores apresentam certa autonomia para a realização de sua atividade profissional.

As identidades profissionais docentes são produzidas a partir de diversos fatores e saberes. Evidencia-se a complexidade que envolve o tema da produção das identidades docentes no âmbito da educação básica, assim como a necessidade de descentralizar as questões pedagógicas do âmbito da escola ou mesmo da sala de aula, situando-as num campo social mais amplo, no campo da cultura, haja vista que os vínculos identitários dos professores se constituem afetados por uma constelação de elementos diversos. Ser professor, considerando as análises produzidas, envolve negociar diferenças culturais e, do mesmo modo, fazer-se em meio a tais diferenças - ora presentes como memória de outros tempos de vida dos sujeitos, ora presentes como parte das experiências mais recentes vividas nos espaços escolares. O lugar do professor se faz entre e nas fronteiras de memórias do ontem e do hoje, que tocam diferentes modelos pedagógicos e epistemológicos, universos paradigmáticos, interpretações do mundo, escolhas (des)feitas e por fazer, transformações operadas nos espaços sociais e institucionais. 
Considerando o que foi exposto, evidenciamos que as identidades docentes não podem ser reduzidas a um único modelo, porque se constituem de forma mestiça, sob a influência de variados fatores. Nesse universo plural, chama a atenção o desafio endereçado aos professores, de que venham a reforçar seus enlaces identitários no sentido de agregar demandas e promover a luta por uma condição outra de produção da docência, talvez mais rebelde, inconformada e autônoma.

\section{NOTAS}

${ }^{1}$ A respeito da ciência e de suas características, convém conferir alguns trabalhos de Boaventura de Sousa Santos em que ele discorre sobre o assunto a partir de duas tendências: o paradigma dominante e o paradigma emergente. Os trabalhos em questão são: Um Discurso sobre as Ciências (1986), Um Discurso sobre as Ciências num período de transição pós-moderna (1988). Pela mão de Alice: o social e o político na pós-modernidade (2000) e A crítica da razão indolente: contra o desperdício da experiência (2001).

${ }^{2}$ Entenda-se sempre: um professor e uma professora.

${ }^{3}$ Referência apresentada pelo autor ISAMBERT-JAMATI, V. O apelo à noção de competência na revista L'Orientation Scolair et Professionelle - da sua criação aos dias de hoje. In: ROPÉ, F.; TANGUY, L. (Org.). Saberes e competências: o uso de tais noções na escola e na empresa. Campinas: Papirus, 1997.

${ }^{4}$ Referências apresentadas pelo autor: (a) DUBAR, C. A socialização: construção das identidades sociais e profissionais. Porto: Porto, 1997 [1991 - original francês]. (b) DUBAR, C. A sociologia do trabalho ante a qualificação e a competência. Educação \& Sociedade, Campinas, v. 19, n. 64, p. 87-103, set. 1998. (c) DUBAR, C. La crise des identités: l'interprétation d'une mutation. Paris: Presses Universitaires de France, 2002.

${ }^{5}$ A este respeito, convém conferir: PEREIRA, G. R. M. Servidão ambígua: valores e condição do magistério. São Paulo: Escrituras, 2001 (Coleção Ensaios Transversais) e TARROW, S. Power in movement: social movements, colective action and politics. Cambridge: University Press, 1997.

${ }^{6}$ Cumpre destacar que cada professor respondeu um total de 9 questões, produzindo, portanto, um total de 9 depoimentos, mais ou menos longos, nos quais revelaram concepções a respeito das identidades docentes, das culturas juvenis e da violência na/da/à escola. No momento da análise, procedemos a um primeiro recorte do corpus relacionado às identidades docentes, ou seja, 200 respostas foram reservadas. Num segundo momento, foi feito novo recorte, separando aqueles depoimentos que ofereciam oportunidade de compreender melhor as representações de docência constituídas pelos professores: 168 depoimentos foram considerados então.

7 Os nomes reais dos professores participantes foram substituídos por nomes fictícios a fim de preservar seu anonimato e em atendimento às normas éticas que regulam a pesquisa com seres humanos. 


\section{REFERÊNCIAS}

BARDIN, L. Análise de conteúdo. Lisboa: Edições 70, 1977.

CATTANI, A. D. América Latina: presença/ausência dos trabalhadores. In: SEFFNER, Fernando (ed.). América 92: V séculos de história, 500 anos de luta. Porto Alegre: Prefeitura Municipal de Porto Alegre, Secretaria Municipal da Cultura, Coordenação do Livro e Literatura, 1992. p. 12-14.

CAVACO, M. H. Ofício do professor: o tempo e as mudanças. In: NÓVOA, A. Profissão Professor. Porto: Porto, 2003. p. 155-191.

ESTEVE, J. M. El malestar docente. 3. ed. Buenos Aires, Argentina: Paidós, 1992.

ESTEVE, J. M. Mudanças sociais e função docente. In: NÓVOA, A. Profissão Professor. Porto: Porto, 2003. p. 93-124.

FISS, D. M. L. Territórios incertos: os processos de subjetivação das professoras da rede pública estadual. 2003. Tese (Doutorado em Educação) - Universidade Federal do Rio Grande do Sul. Faculdade de Educação, Programa de Pós-Graduação em Educação, Porto Alegre, 2003.

LÜDKE, M.; BOING, L. A. Caminhos da profissão e da profissionalidade docentes. Educação \& Sociedade, v. 25, n. 89, p. 1159-1180, set./dez. 2004.

MACHADO, J. V.; FISS, D. M. L. Educação de Jovens e Adultos: encantamento e permanência na escola. Arquivos Analíticos de Políticas Educativas, v. 22, n. X, 2004. Disponível em: <http://epaa.asu.edu/epaa/v22 nX>. Acesso em: 28 abr. 2017.

GARCIA, M. M. A.; HYPOLITO, A. M.; VIEIRA, J. As identidades docentes como fabricação da docência. Educação e Pesquisa. v. 31, n. 1, p. 45-56, jan./abr 2005.

MINAYO, M. C. S. (org.). Pesquisa social: teoria, método e criatividade. 25. ed. Petrópolis, RJ: Vozes, 2007.

NÓVOA, A. Professores: imagens do futuro presente. Lisboa: EDUCA, 2009.

NÓVOA, A. Profissão Professor. Porto: Porto, 2003.

PEREIRA, G. R. M. Servidão ambígua: valores e condição do magistério. São Paulo: Escrituras, 2001. Coleção Ensaios Transversais.

SACRISTÁN, J. G. Consciência e acção sobre a prática como libertação profissional dos professores. In: NÓVOA, A. (org.). Profissão Professor. Porto: Porto, 2003. p. 63-92.

SACRISTÁN, J. G. O currículo: uma reflexão sobre a prática. 3. ed. Porto Alegre: Artmed, 2000.

SANTOS, B. S. A crítica da razão indolente: contra o desperdício da experiência. 3. ed. São Paulo: Cortez, 2001. 
SANTOS, B. S. A construção multicultural da igualdade e da diferença. In: CONGRESSO BRASILEIRO DE SOCIOLOGIA DA UNIVERSIDADE FEDERAL DO RIO DE JANEIRO, 7 . Rio de Janeiro, 4 a 6 de setembro de 1995. p. 1-56. Mimeo.

SANTOS, B. S. Pela mão de Alice: o social e o político na pós-modernidade. 7. ed. São Paulo: Cortez, 2000.

SANTOS, B. S. Um discurso sobre as Ciências. Porto: Afrontamento, 1986. Coleção Histórias e Ideias.

SANTOS, B. S. Um discurso sobre as Ciências na transição para uma Ciência Pós-Moderna, Estudos Avançados, São Paulo, v. 2, n. 2, ago. 1988. Disponível em: $<$ http://www.scielo.br/scielo.php?script=sci_arttext\&pid=S0103-40141988000200007\&lng=en\& nrm=iso >. Acesso em: 20 mar. 2017.

SANTOS, M. A outra globalização. Aula magna. Porto Alegre, Salão de Atos da UFRGS, 10 abr. 1996. Texto digitado. Mimeo.

TARDIF, M. Saberes docentes e formação profissional. 14. ed. Petrópolis, RJ: Vozes, 2012.

TARDIF, M. Saberes profissionais dos professores e conhecimentos universitários. Revista Brasileira de Educação, jan./abr. 2000, n. 13, p. 5-24. Disponível em: $<$ http://teleduc.unisa.br/ teleduc/cursos/diretorio/apoio_5427_368/TARDIF_Saberes_profissionais_dos _professores.pdf>. Acesso em: 22 mar. 2017.

TARDIF, M.; RAYMOND, D. Saberes, tempo e aprendizagem do trabalho na escola. Educação e Sociedade, ano XXI, n. 73, dez. 2000, p. 209-244. Disponível em: <http://www.scielo.br/pdf/es/v21n73/4214.pdf>. Acesso em: 22 mar. 2017.

TARROW, S. Power in movement: social movements, colective action and politics. Cambridge: University Press, 1997. 
Teaching Identity and Primary Education:

\section{The voice of the teachers}

Identidades Docentes y Educación Básica: las voces de los maestros

\section{Resumen}

Este artículo tiene como tema la producción de identidades docentes en los contextos de la escuela básica primaria y busca comprender cómo se produce este proceso, en busca de subsidios, especialmente en Maurice Tardif (2000, 2012), Maurice Tardif y Daniele Raymond (2000), Maria Manuela Alves Garcia, Alvaro Hypolito Jarbas y Vieira (2005). La investigación, realizada en 2013, tiene un carácter cualitativo y cuantitativo. Los datos fueron trabajados a través del Análisis de Contenido desde la perspectiva de Laurence Bardin (1977). Las informaciones obtenidas fueron realizadas a través de preguntas dirigidas a 50 maestros/as de la Educación Básica que actúan en las escuelas públicas, red privada o ambas ubicadas en la ciudad de Porto Alegre (Brasil) y su área metropolitana. Las respuestas de los maestros/as indican que la producción de identidades docentes, en el ámbito de la escuela primaria, ocurre tanto de las experiencias anteriores (pre-profesionales) como de las experiencias profesionales. A pesar de la influencia de las políticas públicas y de los cambios curriculares, el profesional de la educación tiene relativa autonomía en su práctica profesional. En conclusión, se observa que las identidades profesionales docentes se producen a partir de varios factores y saberes, tensiones y contradicciones.

Palabras clave: Identidad Docente. Escuela Básica. Educación Contemporánea.

Enviado em: 01/04/2015

Aprovado em: 05/06/2016 